Áron Dombrovszki

\title{
Pornography and Speech Act Theory - An In-Depth Survey ${ }^{1}$
}

Considering the short history of the feminist philosophy of language, Rae Langton's article "Speech Acts and Unspeakable Acts" was highly influential as one of the first positive research programs within the movement. ${ }^{3}$ In that paper, Langton - using John L. Austin's speech act theory - tries to interpret Catharine MacKinnon's thesis: pornography is a speech that subordinates and silences women. ${ }^{4}$ Despite the importance of the subject, those unfamiliar with certain historical and contextual features of the topic would hardly understand it.

My paper aims to introduce some of the major accounts in this special area at the intersection of speech act theory and feminist philosophy. Rather than just reconstructing Langton's arguments and the most common objections against it, I will take a more holistic approach, examining its surrounding literature as well.

My article has six sections. In Section 1, I contrast the conservative and liberal arguments against pornography and sketch MacKinnon's liberal critique. In Section 2, I give alternative interpretations of MacKinnon's thesis, "pornography is harm". In Section 3, I try to make sense of the prima facie implausible assumption that pornography is speech. In Section 4 and 5, I will analyze the Langtonian theories about subordination and silencing. Finally, in Section 6, I will mention the most challenging problems for Langton's approach, considering the verbal nature of pornography, the limits of the protection of free speech, and the different positions on sexual consent.

\section{Debate in Context: liberal anti-pornography feminism}

The idea that pornography is harmful has a long history, and it appeared in various theories over time. Also, questions about the topic are diverse. What is the exact problem with pornography, and what is the nature of the harm it causes? Is it necessary to fight against porn with legal measures, including censorship or bans? If yes, what are

1 This research was supported by the ÚNKP-20-3 New National Excellence Program of the Ministry for Innovation and Technology from the source of the National Research, Development and Innovation Fund.

2 Langton 1993.

3 Saul - Diaz 2017.

4 MacKinnon 1987. 
the legal and political arguments to support such a rule? In this section, I introduce different answers to these problems in order to prepare for the later discussion.

Usually, those who think that there is a connection between pornography and the silencing of women accept two further consequences of this thesis: pornography causes harm and it requires some kind of legal restriction. There are, however, significant differences between the supporting arguments for these presumptions, mostly originated in one's ideological background. Therefore, it is useful to sketch these competing theories, which helps us to locate MacKinnon in the context of the debate.

It is quite common that conservatism lies behind anti-pornography considerations. Conservatism is not a coherent and unified theoretical framework, but there is an important feature which is more or less core of any conservative approach: the state should protect traditional religious and moral values. Since pornography erodes these values by its inherent obscenity and amorality, regulation by legal measures is required. Nevertheless, this line of argumentation feels somehow outdated and relies on broad assumptions that have weak support. Indeed, there are more modern conservative objections to it. The main focus of these is the individual exposed to the content. One typical objection is that pornography causes sex addiction. If this is true, which is an empirical question, then it can lead to other issues. It may increase sexual harassment and rape because of the large number of sex addicted individuals. Sex addiction can easily lead to divorce, too. These compounding issues altogether threaten the stability of civil society. ${ }^{5}$

Just as we could not define conservatism as a set of theses, liberal standpoints against pornography are diverse. By the term "liberal", I mean a very general notion. An essential presumption is that the state's primary function is to protect its citizens' freedom and equality. However, it seems that from a conservative point of view, it is natural to oppose pornography; this is not the case with liberalism. It is worth mentioning that liberalism is inherently agnostic about the questions of pornography. There are liberal pro-pornography feminists, mostly in the postmodern tradition, who argue that it is an individual's right to make money in this way, and regulating pornography would violate this right. ${ }^{6}$ So, from a liberal point of view, how can one argue against pornography?

Liberal feminists' arguments mainly focus on women's rights; in contrast to conservatism, they reject any argument based on obscenity or religious considerations. This means that creating or distributing sexually explicit content in itself poses no problem at all. Instead, their focus is on the violation of equality and free speech caused by women's subordination in a pornographic content. Motivated by these insights,

5 Wyatt 2009, 538 .

6 Watson 2010, 541. 
MacKinnon argued for two theses: (i) women are currently not equal members of society; (ii) pornography contributes to this inequality. ${ }^{7}$

Understanding the first thesis, we should consider two things. The first one is the unequal distribution of material goods, salaries, and other socioeconomic factors. These observations are supported by empirical research. The second is the higher probability that in a sexual crime - harassment or rape - the victim will be a woman instead of a man. MacKinnon needed to explain this statistical difference; this is why she came up with the second thesis: pornography is why women are more often victims of sexual crime than men. This assumption may seem exaggerated at first, but it is important to note that MacKinnon uses the term "pornography" in a special sense, distinguishing it from erotica, which is any other sexually explicit content:

We define pornography as the graphic sexually explicit subordination of women through pictures or words that also includes women dehumanized as sexual objects, things, or commodities; enjoying pain or humiliation or rape; being tied up, cut up, mutilated, bruised, or physically hurt; in postures of sexual submission or servility or display; reduced to body parts, penetrated by objects or animals, or presented in scenarios of degradation, injury, torture; shown as filthy or inferior; bleeding, bruised or hurt in context which makes these conditions sexual. ${ }^{8}$

According to MacKinnon, pornography can influence its viewers, so that they tend to exhibit aggressive sexual behavior and are willing to accept sexual myths - e.g., women secretly fantasise about rape - than those who avoid pornographic content. These thoughts were influential and led to the Antipornography Civil Rights Ordinance, written by Andrea Dworkin and MacKinnon in 1984, Indianapolis.?

In the ordinance, pornography was defined as content that bribes civil rights. Nevertheless, this law was challenged in court and overturned as unconstitutional not long after its acceptance. The decision was based on the First Amendment of the US Constitution, which guarantees freedom of speech. Using the First Amendment to protect the manufacturing and sale of pornographic content led to unfortunate consequences, not just legally but also philosophically speaking. Because pornography de jure is defined as some kind of speech act, anyone who would like to contribute practically to the debate should regard it as speech too.

7 MacKinnon 1987, 163-197; Langton 1990, 331-336.

8 MacKinnon 1987, 176. Note that this definition begs the question: is pornography harmful? We only need to add the highly intuitive premises that dehumanization and objectification are harmful to arrive at the conclusion. This can be a drawback of MacKinnon's definition, since the moral status of pornography is a complex issue, which is still highly debated.

9 Langton 1990, 336. 
Therefore, MacKinnon argued that pornography is a harmful speech which subordinates and silences women. If she can prove this thesis, she gets closer to her aim to regulate pornography legally. MacKinnon is seemingly in a challenging position: for liberal feminists, free speech is one of the most important civil rights, so why would she limit it by regulating pornography? According to MacKinnon, pornography on its own violates freedom of speech by silencing, which can even lead to rape, so the losses of banning pornography would be negligible compared to the harm that it does now.

To sum up, MacKinnon's argument is based on the idea that pornography in itself violates freedom of speech. Call this thesis "the silencing argument". Since the original silencing argument, taken literally, is trivially false - pornography is not harm, as it is not speech, and certainly does not interfere with anyone's ability to speak -, it drew many objections. In her 1993 article, Rae Langton tried to give a coherent philosophical interpretation of MacKinnon's insights using the speech act theory, and a still ongoing debate was started just after she published her arguments.

In the next section, I continue with the illocutionary approach to pornography, after I differentiated between various interpretations of the thesis of inherent harm caused by pornography. Note that Langton admits that it does not follow from her thesis that pornography should be banned or censored. As Alex Davies showed - and it was also MacKinnon's original aim - providing the legal support for victims to sue the creators of pornographic content would be a desirable goal. Another approach - inconsistent with MacKinnon's views - is to produce more ethical pornographic movies - or "erotic films" -, to crowd out harmful content. However, it is essential to distinguish between pornography's role in silencing and specific strategies to solve this issue: these should be considered separate subjects and I will consider only the first problem here.

\section{Understanding MacKinnon}

So, according to MacKinnon, "pornography is harm" - but what does this mean exactly? We already have answers like watching pornography leads to porn addiction, or that it is morally wrong, but the main question is whether those who are not consumers of pornography - especially women - are really in danger because of its existence. ${ }^{10}$ If the answer is yes, then what causes this harm?

Lori Watson, who analyzed MacKinnon's account, distinguished at least two different interpretations of her thesis. According to the so-called causal model, pornography causes its harm through an intermediary agent. "On this view pornography in itself is

10 Watson 2010, 542, n43. 
not subordinating, rather it causes the subordination of women by altering the beliefs/ desires/motivations for action of men who consume in such a way that women, either as individuals or as a group, are harmed." 11

The other interpretation relies on a conceptual model, followed by MacKinnon and her proponents. Those who accept the conceptual model probably endorse the weaker causal model too. Taking a look at the Antipornography Civil Rights Ordinance, we may get an intuitive picture of what this model is about: men subordinate women who act in porn films. It is just the surface of the issue that the actors are actually depicted in subordinated positions in such films or pictures. The real harm appears when we consider the social network and resources necessary to create content, and we take a look at pornography as a social practice. From this perspective, we can see that everyone suffers the consequences of pornography. Actresses are usually in a vulnerable position, sometimes are victims of human trafficking, slavery, child abuse, or battery. MacKinnon spoke about all of these phenomena when she said that pornography is harm.

Before we start to examine the silencing argument by Langton 1993, we have to take another detour to understand the relevant terms in John L. Austin's How to Do Things With Words. ${ }^{12}$ Austin's aim was to draw attention to an often overlooked fact: speaking is just another form of doing things; hence he coined the term speech act. According to Austin, by saying something, we usually do at least three things. If someone says "Close the window", then at first, the speaker utter an English sentence with a specific meaning and denotation, which Austin calls the locutionary act. Besides the locutionary act, one uttered this sentence with a certain force: it was a demand, or a request, or an order, or whatever was her intention. The complete locutionary act uttered with a certain force is called the illocutionary act. A sentence usually can have different locutionary forces. Furthermore, if the speaker's speech act was successful, it had some effect on the hearer; for example, he closes the window - Austin calls this a perlocutionary effect.

There are two more elements of speech act theory which Langton relies on; however, it is debated whether Austin accepted these. First, when it comes to the speakers' intention, she can carry out an illocutionary act without even intending to do so. For example, as someone's chief, one may intend to advise unintentionally, and her speech act turns out as an order. Second, for a speech act to succeed, uptake - i.e. recognizing the speaker's intention - is a necessary requirement. ${ }^{13}$

In the first sentence of her article, Langton - following MacKinnon - makes it clear that "pornography is speech", ${ }^{14}$ connecting the subject matter with the scholarly on

11 Watson 2010, 542.

12 Austin 1955.

13 Langton 1993, 301.

14 Langton 1993, 293. 
communication and philosophy of language. It is not a usual move, but from this point of view, it is possible to apply Austin's distinctions to understand MacKinnon's thesis better: pornography has the illocutionary force of subordination. However, is this a successful strategy? There are further problems which we should investigate in order to answer this question. Can we seriously say that "pornography is speech" and use Austin's theoretical framework to investigate the phenomena? (Section 3.) If the answer is yes, can we say that subordination is a unique illocutionary force of a speech act? (Section 4.) What is the exact connection between subordination and silencing? (Section 5.) How can pornography silence its victims? (Section 6.) I will consider these issues in the subsequent sections.

\section{Pornography as Speech}

It is one thing to consider pornography as speech for legal reasons, but it is an entirely different matter to examine it as verbal content with philosophical aims in mind. There is an extensive debate on the possibility of this, which we will introduce here, mainly relying on Louise Anthony's article. One trivial approach to the discourse is to take pornography as a kind of speech literally. However, it is hard to see how this can work: there are erotic novels which we can call "pornography", but the term denotes pictures, videos, movies, typically using pictorial representation, which is essentially different from linguistic representation. ${ }^{15}$ Linguistic representation is intensional, so they are considered meaningful, which would be hard to say about pictures. ${ }^{16}$ Even if we ascribe some kind of meaning to pictures, this meaning will be polysemic, so the illocutionary force would also be indeterminate. ${ }^{17}$ This observation contradicts Langton's thesis which states that pornography has the illocutionary force of subordination.

Besides, actors utter sentences in porn movies, which also can be the subject of Langton's thesis: "pornography is speech". There are two problems with this approach. First, these sentences are uttered in a fictional context. Like those uttered by a character in a movie or a play, these speech acts do not have illocutionary force; they are merely parasitic speech acts. ${ }^{18}$ Secondly, the characters in porn movies usually do not use the kinds of speech acts required by the Langtonian theory. According to Anthony, a genuine subordinating speech act in the movie should be uttered by the director - or any-

15 Anthony 2011.

16 Fodor 2007.

17 Searle 1968.

18 Searle 1975. Alternatively, one can think that a special kind of fictive illocutionary force comes into play in these cases, see Currie 1985. 
one else who is not represented as a character - and should say something like the following: "I hereby subordinate women!", a sentence which is not very frequently said in porn films. The conclusion is that even if pornography has some kind of a "message", that must be implicit content, which is better analyzed with the Gricean theory of implicatures than the Austinian theory of speech acts. ${ }^{19}$

Jennifer Hornsby is another scholar who tried to solve this issue, emphasizing three features of porn that make it hard to count these films as communicative speech acts. (i) Viewers are rarely able to differentiate an exact message which is communicated. (ii) Even if one can distinguish an actual message conveyed through the medium, this message certainly has not been intended by the creators. (iii) This content can not be recognized as an intentionally conveyed message. ${ }^{20}$

Hornsby proposes a unique solution to this problem. Even if Austin's theory does not contain the analysis of non-communicative acts, it is possible to extend it with the notion of forceful acts, which can cover the phenomena in question. According to Hornsby, expressing propositional content is not a necessary requirement - hence these are non-communicative - for an act to have an illocutionary force: in particular, pornography has the illocutionary force of subordination. This illocutionary force does not come from authorial intentions, nor from the dialogues in the films, but rather "it is something achieved in its consumption". ${ }^{21}$ This approach is not unorthodox; even John Searle provides examples of certain acts ${ }^{22}$ expressing illocutionary force without propositional content.

It is probably true that not everyone is pleased with Hornsby's solution. Nevertheless, it is crucial to distinguish between two different problems in this area. First, if one has practical aims in mind, accepting the court's premise that pornography is de jure speech is a necessary step. The usual way is that lawyers try to show that pornography should not be protected by the law of free speech, which was MacKinnon's original motivation to develop her harmful speech account - and making some trouble for philosophers of language. It would be interesting to see that someone argues against pornography being a speech to conclude that free speech laws should not protect it.

I think that the de facto communicative content status of pornography is still an open question. Even though many promising approaches have been developed during the years, the thesis still needs more justification due to its revolutionary nature. However, most philosophers keep an eye on the practical issues, so they presume that it is possible to discuss topics on pornography as it were a kind of speech. For this reason,

19 Grice 1975.

20 Hornsby $2011,382$.

21 Hornsby 2011, 383 (emphasis in the original). See also Langton 2011.

22 E.g., "Hooray!" or “Ouch!" See Searle 1969. 
I will accept this assumption from now on, and in the next section, I continue with Langton's theory of subordinating illocutionary acts.

\section{The Illocutionary Act of Subordination}

Langton's first problem is this: can we even consider subordination an illocutionary act? Her answer is positive: for example, it is plausible to think that a sign on a coffee shop door that says "whites only" has the illocutionary force of subordination. ${ }^{23}$ Its intended perlocutionary effect is the separation of whites and other people of color and keeping racist attitudes alive.

If we can accept that the sign mentioned above can have the illocutionary force of subordination, then the next question is: what are the necessary and sufficient conditions for a speech act to have this illocutionary force? Langton specifies three attributes of the illocutionary force of subordination. (i) It ranks between different social groups. (ii) It legitimates discriminatory behavior by depriving the power of underprivileged groups. (iii) Only members of privileged groups can subordinate members of underprivileged groups. An essential addition to these conditions is that (i)-(iii) happen unjustly.

According to Langton, pornography as a speech act fulfills at least two of the three conditions: "Pornography is said to rank women as sex objects 'defined on the basis of [their] looks [...] their availability for sexual pleasure. [...] Pornography sexualizes rape, battery, sexual harassment, [...] and child sexual abuse [...] it celebrates, promotes, authorizes and legitimates them' These descriptions bear on the claim that pornography subordinates." ${ }^{24}$ She thinks that it is plausible to think that pornography has the illocutionary force of subordination due to these features. It has the probable perlocutionary effects of disposing viewers to believe rape myths and victim-blaming. It would be hard to deny that all of this is unjust, so it also fulfills the additional requirement.

Since proper authority is required as well, Langton argues that in the discourse about sex, unfortunately, pornography has authority. ${ }^{25}$ Besides this, she also considers the connection between authors' intentions and the illocutionary force of a speech act. Those who create these films probably do not want to subordinate or silence women -

23 Prima facie it seems that primarily, the sign has some kind of directive illocutionary force, and subordination is rather a secondary illocutionary force. However, Langton does not consider the theory of secondary illocutionary forces, which would be an interesting addition to her view.

24 MacKinnon 1987, 163-197, cited by Langton 1993, 307 (italics in the original denoting illocutionary verbs).

25 Langton 1993, 312. 
they aim to make a profit. Langton argues that our speech acts may have a different illocutionary force than intended, as I mentioned in Section 2: e.g. a commander may try to advise his inferior, but due to the hierarchical nature of the military, his speech act will count as an order. ${ }^{26}$

\section{Silencing Argument and Speech Act Theory}

The most crucial part of Langton's article is perhaps the part where she presents her silencing argument. Even though the principle has many interpretations, prima facie it seems implausible to think that pornography silences women: despite the movies being still out there, women can speak. It is a more promising approach to connect the silencing argument with the subordination thesis: pornography, due to its illocutionary force, subordinates women and contributes to the spread of rape myths, creating an unsupportive or even offensive communicative environment. This environment can contribute to women's silencing by blocking certain speech acts, for example, the refusal of sex.

In what ways can a woman be silenced? Langton has six examples of situations where someone makes an utterance but it fails. The first four examples are general cases in casual situations; the last two are from sexual discourses. Let us see the first group of examples. ${ }^{27}$ The first thought experiment was originally presented by Donald Davidson, and it is about the illocutionary act of warning. Suppose that we are in the theatre watching a play. The play is currently at a stage where, according to the story, there is supposed to be a fire on stage. However, the building catches on fire simultaneously, and the actors cannot warn the audience by shouting "Fire!" because everyone thinks that this is all part of the play. The second example is marriage: two gay men say in the right context "Yes", but their speech act does not have the intended perlocutionary effect because same-sex marriage is not legal there. The third example is voting in apartheid countries: in South Africa, if a white person draws a circle in the box and puts the paper in the ballot box, it counts as a vote. If black people do the same, their acts will not qualify as an act of voting; it is an unspeakable act for them. The fourth example is divorce: according to Islamic law, if a man utters three times the expression "mutallaqua", he successfully divorced his wife. As opposed to this, if a woman utters the expression three times, it does not have any effect.

26 Langton 1993, 309. Note that this is a debated question, and Langton does not provide strong arguments to defend her position. One can think that the commander just gave the advice as he intended, despite the military hierarchy.

27 Langton 1993, 316-317. 
Langton considers these cases as casual forms of silencing. However, Nicole Wyatt draws attention to a relevant difference between the Davidsonian case and the other three cases. Marriage, voting, and divorce are highly regulated acts; most requirements are described legally. In these cases, the problem which causes the "silencing" clearly is that the speakers do not fit the requirements for a successful act. ${ }^{28}$ It would be strange to consider these as examples of silencing.

According to Wyatt, the example of the theatre fire differs in at least two ways. First, the illocutionary act of warning has no conventions: one can cry loud "Fire!" or one can put a sign on the fence indicating that the dog bites, or one can use hand signals if one thinks that the other people could not hear my voice - these are all appropriate ways to warn someone about something, none of them are part of any convention or legal code. Secondly, it seems that the nature of failure is different: in the cases of marriage, divorce, or voting, the speaker's stance is impossible. The only way to convey these speech acts is to change conventions, which is a slow process with a high possibility of social resistance - in contrast to these, a highly motivated actor can somehow warn his audience. Even though Davidson proves that in theory every speech act of the actor can be interpreted as it is just a part of the play, taking into consideration a real scenario, it is implausible to suppose that the context of the play overwrites everything, and when the actor jumps off the stage and runs away, the viewers indeed start to suspect that something is not right. This difference will be important later.

Let us examine the example of silencing in the context of sexual discourses. ${ }^{29}$ The first example is refusal. It happens that women try to refuse men, but their speech act fails, which leads to rape. There are two ways in which refusal can fail. In the first case, the hearer recognizes the speaker's intention but he does not care - this is a typical example of sexual assault. From a philosophical standpoint, the other case is more relevant to Langton: the speaker tries to refuse sex but the hearer is not able to recognize her intention - perhaps due to the rape myths encoded in pornography, he believes that a woman never says no to sex, or "no" means "yes" - so her speech act fails. The second example is protest. This example comes from the context of porn actress Linda Lovelace's book Ordeal. In the book, she tells her story about the filming of Deep Throat, where she was mistreated and abused in order to play the part perfectly. The author's intention was to protest against women's subordination in the porn industry, but her book was sold later as an erotic novel for adults. This means that Linda Lovelace's protest was not successful; the audience interpreted her story as fiction. These two examples are similar to the Davidsonian cases in the sense that the illocutionary uptake was missing because of contextual elements, not because it violated a particular rule.

28 Wyatt 2009, 137. See also Austin 1955 for a collection of different kinds of failures.

29 Langton 1993, 320-322. 
How can we analyze these two examples? ${ }^{30}$ As Austin distinguished between locutionary, illocutionary, and perlocutionary acts, different levels of silencing can be distinguished too. On a locutionary level, it is possible to silence someone by stuffing something into her mouth, by playing loud music, or by interfering with the communication lines. In these cases, even hearing the speaker is impossible. Another case is when the hearer ignores the speaker, e.g. someone asks me to close the window, but I do not do anything. Langton calls this perlocutionary frustration. Finally, it is possible to create communicative contexts where the speakers' illocutionary intentions are hard or even impossible to recognize. This is called illocutionary disablement, which leads to the incapability of the hearer's uptake.

Using these tools, we can reconstruct Langton's silencing argument in the following way. Pornography, with its subordinating illocutionary force, creates a hostile environment of communication for women about sex by promoting rape myths that they enjoy rough or violent treatment and never refuse sexual advances. Those affected by these myths will not understand women's refusal of sex, because they will think that all of this is just "part of the game". In the worst case scenario, they will interpret it as consent, so the victim's speech acts were silenced by illocutionary disablement, leading to possible rape.

Langton's silencing argument - based on illocutionary disablement - later inspired feminist philosophers to propose further developments on the topic. In her 2016 article, Laura Caponetto examined these novel silencing arguments using John Searle's speech act theory. The first one is Mary Kate McGowan's sincerity-silencing. The idea relies on the distinction between the sincerity condition, the intention to be sincere, and the intended illocutionary force. The speaker is silenced sincerely if the intended illocutionary act has a sincerity requirement, the speaker fulfills this requirement but the hearer does not recognize it. ${ }^{31}$ Another suggestion by McGowan is the authority silencing, which comes into place when the hearer cannot recognize - or recognized somewhat mistakenly - the speaker's authority on a given discourse. According to McGowan - following Searle in this respect - certain speech acts have an authority required to be successful, as the order: a lieutenant cannot give commands to a general due to the specified hierarchy in the military. McGowan argues that refusal is also an authoritative act, not necessarily recognized by everyone, because the speaker has authority over her own body. Caponetto differentiates this account by highlighting a distinction between the examples of the theatrical actor and the refusal. In the case of the actor, the hearers mistakenly think that the actor's warning was just a part of the

30 Caponetto 2016, 186.

31 McGowan 2014; Caponetto 2016, 187. 
play - so it was a sincerity silencing due to the lack of illocutionary force -, in the case of the refusal, it has an illocutionary force, but it is recognized mistakenly. ${ }^{32}$

These are all exceptional additions to the scholarly on illocutionary silencing, but in the following, I will focus exclusively on Langton's silencing argument, as it had the most significant impact. In the next section, I will examine the most common arguments against Langton's proposal.

\section{Problems with Langton's silencing-argument}

I have already examined the issue of considering pornography as some kind of speech in Section 3: from a philosophical point of view, it raises serious problems, but if we have practical aims in mind, it is justifiable. However, even if we are committed to the view that pornography is speech, what guarantees that Austin's speech act theory is the best tool to analyze the phenomena?

Jennifer Saul raised an issue against Langton's approach based on a presumption of the framework, which says that only communicative acts in certain contexts can be speech acts. Pornography as a cinematic genre is not such content, so it is dubious whether it can have any illocutionary force. ${ }^{33}$ If we can not ascribe illocutionary force to pornography, then evidently, it can not have the illocutionary force of subordination, either. Saul makes modifications to Langton's original theory to solve this issue: the fact that pornography itself can not have any illocutionary force does not mean that it can not have illocutionary force in certain contexts where the film is played. So, porn does not have illocutionary force, only its views in certain contexts.

If we incorporate this idea into Langton's theory, we see that views of pornographic content have the illocutionary force of subordination. According to Saul, this is an implausible account, since there are several different contexts in which one can watch pornography: at home, in the cinema, in a laboratory carrying out experiments, or in a feminist workshop for demonstrative purposes. Of course, the problem is that these contexts are very diverse, and it seems to be a mistake to say that each of these plays bears the illocutionary act of subordination. But the weaker yet plausible thesis that in some cases pornography has the illocutionary force of subordination seems too weak for Langton's purposes. Saul suggests that if Langton cannot strengthen her account, then it would be a good step to leave the illocutionary approach - and Austin's speech act

32 Caponetto 2016, 188.

33 Saul 2006. 
theory altogether - behind to find a better framework to analyze the subordination of women by pornography.

In his critique, Alexander Bird tried to show that Langton made a mistake about the requirements of a successful speech act: uptake is not one of them. In Langton's theory, the presumption that the speaker cannot refuse due to the lack of illocutionary uptake is a key element - leading to the consequence that no act of refusal has been made. Bird relies on Jacobson's ethical principle to show an unwanted consequence of Langton's proposal: if the victim has not refused the sexual advances of the rapist, he can not be blamed or punished for his crime, because he did nothing against her will. Questions of consent are a complex topic, and even though the lack of explicit refusal does not mean consent, it seems that the rapist's crime is not as serious on Langton's account as it seems intuitively. ${ }^{34}$

Bird raises a further issue. At first, he mentions examples of successful speech acts where the uptake was not guaranteed. For example, judicial judgments are still successful, even though nobody recognizes this. Alternatively, let us suppose that John writes his will, but the paper has gone missing, and the family only finds it after years have passed. The act of making John's will was successful when he wrote it; it does not matter that nobody found or read it. Surrendering in a battle is also such an act. It is successful, even if the opposing force does not recognize the speaker's intention. ${ }^{35}$

Considering Bird's examples, it is plausible to say that not every speech act requires an uptake to succeed. Bird's task is now to show that refusal is such an act. He does this by illustrative examples and analogies. Suppose that Bill got a wedding invitation, but he thinks that the wedding is just a joke, as he never heard of his friend to be proposed or even that he has a fiancée. In this case, Bill clearly has not recognized the speaker's intention - which was invitation - but it would be a mistake to say that Bill was not invited to the wedding.

If invitation is a speech act that does not require uptake, then it is plausible to suppose that refusal is such an act too. Bird's example is the case of Jacques, the arrogant chef. Jacques thinks that everyone wants to taste his delicious food, and if someone refuses to get another meal, they must be too shy to ask for more. If Langton is right, then when someone refuses to take Jacques's meal and he fails to recognize this and still gives them more food, no act of refusal has happened. However, this seems implausible: Bird thinks that there was a refusal, only Jacques was unwilling to accept it, as in the original case of the refusal of sex. ${ }^{36}$

34 Jacobson 1995; Bird 2002, 3.

35 Bird 2002, 7-10.

36 Bird 2002, 10-12. 
Alex Davies reacts to Langton's theory from another point of view: he draws attention to the fact that she relies on an unpopular approach to freedom of speech, which does not make her account incoherent, but makes it disadvantaged in contrast to other theories which rely on the mainstream theory. ${ }^{37}$ Let us see how Davies reconstructs Langton's silencing argument in five points:

(1) Assumption1: Langton claims that certain special illocutionary acts (SIAs) are protected speech.

(2) Assumption2: If uptake fails for an illocutionary act, then there was no illocutionary act.

(3) Assumption3: Pornography causes failed uptake for SIAs.

(4) (2) and (3): Pornography silences SIAs.

(5) (1) and (4): Pornography silences protected speech. ${ }^{38}$

Davies sketches the so-called Millian view of free speech: everyone has the right to express their opinion without restrictions, but this right does not grant that everyone should be heard or their intention be acknowledged. In terms of speech act theory, the speaker's illocution is not protected, only their locution is. Davies illustrates the problem with an example:

[I]n a lecture on Frege, a lecturer may express her own view about logicism while the students unreasonably confuse this for a presentation of Frege's view of logicism. Did she therefore fail to say what she thinks? Her capacity to give voice to her own voice is not that enslaved to the doziness of her audience. But then the way in which speech is supposed to be silenced by pornography, according to Langton's silencing argument, doesn't apply to protected speech on the Millian conception. ${ }^{39}$

Nevertheless, Langton made her opposition to the Millian standpoint explicit: the protection of free speech should incorporate the protection of certain illocutionary acts, too. ${ }^{40}$ Davies accepts that it is possible to extend the protection of the freedom of speech to the illocutionary acts, but he is skeptical about the protection of uptake. Davies' point is that even though this unorthodox theory of free speech is not inconsistent, it poses significant disadvantages compared to rival theories. At the end of his paper, Davies presents a better version of the silencing argument, which does not face this problem.

37 Davies 2014, 4-5.

38 Davies 2014, 4.

39 Davies 2014, 5.

40 Hornsby - Langton 1998. 
Besides the three objections mentioned above, the notion of "consent" and "refusal" - critical elements in Langton's silencing argument - also generated a considerable debate. ${ }^{41}$ Two basic models are available in the discussion: the "no means no" approach is more permissive: until the woman explicitly says "no", the sexual act is consensual. If we use this model to understand Langton's silencing argument, Jacobson's objection immediately arises: if the woman is not able to express her refusal, then we have to consider the sexual act consensual, which excuses the rapist from his crime.

However, the affirmative model is more common: according to this view, the consensual sexual act requires explicit verbal consent. It seems that Langton's theory only works if we accept the affirmative model, which allows an escape route from Jacobsontype objections.

Joan McGregor examines the notion of consent from a legal perspective, emphasizing that the focus should be on protecting women's autonomy over their bodies. The laws in the US require explicit refusal and physical harm of the victim to make it a case of rape. According to McGregor, both requirements are too strong. In most cases, there is no opportunity for an explicit refusal. Against the traditional rape myths, sexual harassment and rape are expected in an everyday environment of colleagues, friends, or even in a marriage by manipulating, deceiving, and threatening women. According to McGregor, even in situations where there is explicit consent, there is a place for suspicion, e.g. consent between the employer and employee is not always honest. In the case of physical harm, McGregor states that "the law should make it clear that sexual activity is inconsistent with violence". 42

McGregor's insights seem intuitively correct, but there are circumstances where the matter is not that simple in practice. In the BDSM subculture, participants often rely on master-servant roles, making it hard to interpret the notion of consent. In some of the roleplays, giving and receiving pain is the primary source of pleasure; in some cases, a "conventional" sexual act does not even happen. That it is consensual can be the only distinction between a BDSM scenario and rape, especially in games where participants imitate sexual assault. Potentially every situation like this can lead to violated consent. D.J. Williams - who is also an active member of the subculture - acknowledges that most participants have been in situations that were not consensual, and to prevent cases like these, he created a special communicative framework for BDSM participation. ${ }^{43}$

41 These issues are relevant due to Langton's assumption that pornography has the effect of creating communicative situations which make rape easier to commit through making the rapist more insensitive to the victim's real communicative intentions. Keep in mind that this assumption needs empirical support.

42 McGregor 1996, 208.

43 Williams 2004. 
It is not necessary to go this far to understand how complex the issue of consent is: "while perhaps it might be helpful if people said exactly what they wanted - if they were direct, clear and obvious all the time and in every way - this is not the nature of reality. While frequent and direct communication is desired, there is always more that is left unsaid." ${ }^{44}$ However, I think these questions are essential when we try to analyze Langton's silencing argument, since her main point is that there are some cases of rape where the rapist cannot recognize the refusal, and he thinks that the sexual act is consensual.

As I mentioned earlier, the Jacobsonian objection, which points to the silencing argument's unwanted consequences - i.e. the rapist is not responsible for the crime he committed due to his beliefs - can be eliminated by using a different notion of consent. It can be a beneficial theoretical decision; however, practically it causes trouble, since we turn away from the legal definition of consent. The problem is that Langton's motivation comes from the desire to be consistent with legal practices: this is why MacKinnon started to speak about pornography as a kind of speech, and Langton tried to make it a coherent philosophical view. If we - by this presumption - try to be consistent with the law, then we can not solve this issue by relying on another notion of consent. So, the Jacobsonian issue is still open.

Wyatt's insights mentioned above posed another issue: refusal, as in the example of the actor, is not entirely impossible; it is just harder because of certain circumstances. As the actor can communicate his intentions if he tries hard enough, similarly, Langton's proposal seems unlikely in real life: "The problem with this is that it does indeed seem extremely implausible to suggest that a common way in which rapes happen is by the rapist simply, sincerely, and consciously believing that the woman (equally simply, sincerely, and consciously) means 'yes' when she says 'no'. Rape is not some kind of hilarious sitcom-style case of crossed wires." ${ }^{45}$ In a real life scenario, it is hard to imagine that the victim was unable to express her refusal, and the rapist was unable to interpret it as an honest act thereof.

Besides these issues, the communicative model that Langton proposes is too simple: consent and refusal is not just a one-word "yes" or "no" discourse, but usually embedded in a more complex discursive situation. It makes it questionable whether Langton's description is adequate for the analysis of the situation at all.

Finally, the definition of pornography has changed over time and lost its original meaning. Of course, it should not be a problem, since the term has an intuitive everyday meaning and use, but MacKinnon altered it, giving it an entirely new definition, which is not identical to the word's intuitive meaning (see Section 1). Those who con-

44 Williams 2004.

45 Finlayson 2014, 781. However, Finlayson tried to defend Langton against this objection. 
tribute to this debate should clarify which sense they rely on in order to avoid confusion.

Considering some of these issues, Lorna Finlayson chose the motto "MacKinnon, not Austin!" in her 2014 meta-article on the debate. Her article's main point is that something has gone wrong in the academic discourse following Langton, focusing mainly on meticulous questions, such as the proper distinction between illocution and perlocution, the status and definition of pornography, and the like. Meanwhile, the practical aims of the whole issue are now blurred by endless verbal debates. Finlayson argues that feminist philosophers should return to MacKinnon's original text, because even though analytic feminists "see their project as one in the service of greater clarity and rigor, thereby potentially increasing the accessibility and persuasiveness of the silencing argument to an analytic audience", ${ }^{46}$ in these debates, the most critical questions are left unanswered.

\section{Bibliography}

Anthony, Louise. 2011. "Against Langton's Illocutionary Treatment of Pornography." Jurisprudence 2/2: 387-401. DOI: 10.5235/204033211798716826.

Austin, John L. 1955. How To Do Things With Words. Oxford: Clarendon Press.

Bird, Alexander. 2002. "Illocutionary Silencing." Pacific Philosophical Quarterly 83/1: 1-15. DOI: $10.1111 / 1468-0114.00137$.

Caponetto, Laura. 2016. "Silencing Speech with Pornography." Phenomenology and Mind 6/2: 183-191. DOI: 10.13128/Phe_Mi-20118.

Curry, Gregory. 1985. "What is fiction?" The Journal of Aesthetics and Art Criticism 43/4: 385392. DOI: $10.2307 / 429900$.

Davies, Alex. 2014. "How to Silence Content with Porn, Context and Loaded Questions." European Journal of Philosophy 24/2: 1-25. DOI: 10.1111/ejop.12075.

Finlayson, Lorna. 2014. "How to Screw Things with Words." Hypatia 29/4: 774-789. DOI: 10.1111/hypa.12109.

Fodor, Jerry A. 2007. “The Revenge of the Given." In Contemporary Debates in Philosophy of Mind, edited by B. McLaughlin - J. Cohen, 105-117. Oxford: Blackwell.

Grice, Herbert Paul. 1975. "Logic and Conversation." In Syntax and Semantics 3: Speech Acts, edited by P. Cole - J. L. Morgan, 41-58. New York: Academic Press.

Hornsby, Jennifer - Rae Langton. 1998. "Free Speech and Illocution.” Legal Theory 4/1: 21-37. DOI: $10.1017 /$ S1352325200000902.

Hornsby, Jennifer. 2011. "Subordination, Silencing, and Two Ideas of Illocution." Jurisprudence 2/2: 379-385. DOI: 10.5235/204033211798716826.

46 Finlayson 2014, 786. 
Jacobson, Daniel. 1995. "Freedom of Speech Acts? A Response to Langton." Philosophy and Public Affairs 24/1: 64-78. DOI: 10.1111/j.1088-4963.1995.tb00022.x.

Langton, Rae. 1990. "Whose Right? Ronald Dworkin, Women, and Pornographers." Philosophy and Public Affairs 19/4: 311-359. DOI: 10.1093/acprof:oso/9780199247066.003.0007.

Langton, Rae. 1993. "Speech Acts and Unspeakable Acts." Philosophy and Public Affairs 22/4: 293-330. DOI: 10.1093/acprof:oso/9780199247066.003.0002.

Langton, Rae. 2011. "Response." Jurisprudence 2/2:425-440. DOI: 10.5235/204033211798716826.

MacKinnon, Catharine. 1987. Feminism Unmodified. Massachusetts: Harvard University Press.

McGowan, Mary Kate. 2014. "Sincerity Silencing." Hypatia 29/2: 458-473. DOI: 10.1111/ hypa.12034.

McGregor, Joan. 1996. "Why When She Says No She Doesn't Mean Maybe and Doesn't Mean Yes: A Critical Reconstruction of Consent, Sex, and the Law." Legal Theory 2/3: 175-208. DOI: $10.1017 / S 1352325200000483$.

Saul, Jennifer. 2006. "Pornography, Speech Acts and Context." Proceedings of the Aristotelian Society 106/1: 229-248. DOI: 10.1111/j.1467-9264.2006.00146.x.

Saul, Jennifer - Esa Diaz-Leon. 2017. "Feminist Philosophy of Language." In The Stanford Encyclopedia of Philosophy (Fall 2017 Edition), edited by Edward N. Zalta. [https://plato. stanford.edu/archives/fall2017/entries/feminism-language/] (2021.01.16.)

Searle, John. 1968. "Austin on Locutionary and Illocutionary Acts." Philosophical Review 77/4: 405-424. DOI: $10.2307 / 2183008$.

Searle, John. 1969. Speech Acts: An Essay in the Philosophy of Language. Cambridge: Cambridge University Press.

Searle, John. 1975. "The Logical Status of Fictional Discourse." New Literary History 6/2: 319332. DOI: $10.2307 / 468422$.

Watson, Lori. 2010. "Pornography." Philosophy Compass 5/7: 535-550. DOI: 10.1111/j.1747-9991.2010.00292.x.

Williams, D. J. 2014. "From 'SSC' and 'RACK' to the '4Cs': Introducing a New Framework for Negotiating BDSM Participation" Electronic Journal of Human Sexuality 17/1. [https://www. researchgate.net/publication/271854517_From_SSC_and_RACK_to_the_4Cs_ Introducing_a_New_Framework_for_Negotiating_BDSM_Participation] (2021.01.16.)

Wyatt, Nicole. 2009. "Failing to Do Things With Words." Southwest Philosophy Review 25/1: 135-142. DOI: 10.5840/swphilreview200925114. 